\title{
Corneal dystrophy-perceptive deafness syndrome
}

INSERM

\section{Source}

INSERM. (1999). Orphanet: an online rare disease and orphan drug data base. Corneal dystrophy-perceptive deafness syndrome. ORPHA:1490

Corneal dystrophy-perceptive deafness (CDPD) or Harboyan syndrome is a degenerative corneal disorder characterized by the association of congenital hereditary endothelial dystrophy (CHED; see this term) with progressive, postlingual sensorineural hearing loss. 